\title{
Figurative Idiomatic Language: Strategies and Difficulties of Understanding English Idioms
}

\author{
Nisreen Al-Khawaldeh (Corresponding author) \\ Department of English Language and Literature, The Hashemite University, P.O. Box 330127, Zarqa 13133, Jordan \\ E-mail: nal-khawaldeh@hu.edu.jo \\ Abdullah Jaradat \\ Department of English Language and Literature, The Hashemite University, P.O. Box 330127, Zarqa 13133, Jordan \\ E-mail: abdjaradat@hu.edu.jo \\ Husam Al-momani \\ Department of English Language and Literature, The Hashemite University, P.O. Box 330127, Zarqa 13133, Jordan \\ E-mail: Husams@hu.edu.jo \\ Baker Bani-Khair \\ Department of English Language and Literature, The Hashemite University, P.O. Box 330127, Zarqa 13133, Jordan \\ E-mail: bakribakr@yahoo.com
}

Received: 22-05-2016

Published: 01-11-2016
Accepted: 07-08-2016

doi:10.7575/aiac.ijalel.v.5n.6p.119
Advance Access Published: September 2016

URL: http://dx.doi.org/10.7575/aiac.ijalel.v.5n.6p.119

\begin{abstract}
Learning idioms which is considered a very essential part of learning and using language (Sridhar and Karunakaran, 2013) has recently attracted a great attention of English learning researchers particularly the assessment of how well Asian language learners acquire and use idioms in communication (Tran, 2013). Understanding and using them fluently could be viewed as a sign towards language proficiency as they could be an effective way to give students better conditions to enhance their communication skills in the daily context (Beloussova, 2015). Investigating how idiomatic expressions are dealt with and processed in a second language or foreign language is an issue worth examining further since it may give language teachers a better idea of some of the strategies language learners use in order to interpret figurative language. Despite their importance, learning and using English idioms by Arab EFL learners have not been investigated extensively, and no research has been conducted on Jordanian students' idiomatic competency. Thus, the researcher decided to work on these un-tackled issues in the Jordanian context. Most idioms-based investigations are the difficulties Jordanians learners of English face when translating them into Arabic (Hussein, Khanji, and Makhzoumi, 2000; Bataineh and Bataineh, 2002; Alrishan and Smadi, 2015). The analysis of the test showed students' very poor idiomatic competence; particularly a very limited awareness of the most frequently used idioms despite their overwhelming desire to learn them. Data analysis of the questionnaire revealed the strategies students use and the problems they face in understanding and learning idioms.
\end{abstract}

Keywords: Idioms, idiomatic competence, figurative meaning, language proficiency, idioms learning strategies

\section{Introduction}

It is widely acknowledged that there is a worldwide demand for English language learning due to its supremacy in international business, technology, and science (Carkin, 2005; Ababneh and Al-Momani, 2011). Learning idioms which is considered a very essential part of learning and using language (Conklin, 2008, Roberto de Caro, 2009; Sridhar and Karunakaran, 2013) has recently attracted a great attention of English learning researchers particularly the assessment of how well Asian language learners acquire and use idioms in communication (Tran, 2013). Understanding and using them fluently could be viewed as a sign towards language proficiency as it could be an effective way to give students better conditions to enhance communicative skill in the daily context (Saleh and Zakaria, 2013; Beloussova, 2015). Investigating how idiomatic expressions are dealt with and processed in a second language or foreign language is an issue worth examining further since it may give language teachers a better idea of some of the strategies language learners use in order to interpret figurative language. However, it seems that they have not been given much attention by teachers and students. 


\section{Literature review}

A language is full of idiomatic expressions which are similes, metaphors, phrasal verbs, and figurative speech (Cooper, 1998). An idiom (e.g. throw off balance, hedge your bets and smell a rat...etc.) is defined as "a term used in grammar and lexicology to refer to a sequence of words which are semantically or syntactically restricted, so that they function as a single unit. From a semantic viewpoint, the meaning of the individual words cannot be summed to produce the meaning of the idiomatic expression as a whole. From a syntactic viewpoint, the words do not often permit the usual variability they display in other contexts" (Crystal, 1991: 170). Fowler (1996) simply views it as a phrase where the words together have a meaning that is different from the dictionary definitions of the individual words. That is why English learners find idiomatic expressions very hard to understand. This is even when the use and meaning of the target idioms are similar in two languages (Kellerman, 1986).

English is a language rich of idioms (Brenner, 2011; Zyzik, 2011). As claimed by De Caro (2009), without the use of idioms, English would lose much of its diversity both in spoken and written texts. Glucksberg (2001) argues that learning idioms facilitates acquiring information about a language's culture as they are culture specific and it is difficult to find their equivalents in every language. Ellis (1997) and Yorio (1989) Celce-Murcia (2008) add that satisfactory awareness and suitable use of idioms in target languages are vital signs of communicative competence and the ability to successfully express feelings and thoughts in that language. Trosborg (1985) found a correlation between learners' ability to understand the meaning of unknown metaphorical idioms and their proficiency in the target language. A quote from Oxford Dictionary of Phrasal Verbs (1994:422) could summarize their importance in learning English language: "Knowledge of a wide range of idiomatic expressions, and the ability to use them appropriately in speech and writing, are among the distinguishing features of a native-like command of English".

Mäntylä (2004) classifies idioms into three types according to their transparency though the level of transparency is sometimes arguable. They are either transparent idioms where the literal and figurative meanings are linked to each other, semi-transparent idioms where there is a relation between literal and figurative meanings but not transparent, or opaque idioms where the literal and figurative connotation are completely different. Language learners are anticipated to be capable of using some less common idiomatic expressions (British Council, 2012).

Idioms and idiomatic expressions differ in the predictability of their meaning. In other words, some of them can be recognized immediately once the first word is uttered or seen while others can only be identified when the key word is recognized (i.e. hit the nail on the head). It is possible that the idiomatic expression might be intended literally up until when the key head word is recognized (Glucksberg, 2001: 70-71). Idiomatic expressions are originated from different sources as (Stathi, 2006) illustrates: from work (e.g. don't count your chickens), rural life (e.g. eat like a horse), from science and technology (e.g. I need to recharge my batteries), literature and history (e.g. the streets are paved with gold), body parts (e.g. I speak from the bottom of my heart), feelings and emotions (e.g. in high spirits).

Researchers differ in viewing the strategies through which idioms are processed, stored and retrieved (Lexicon, Qualls, O'Brien, Blood, and Hammer, 2003). Bobrow and Bell (1973) suggest that idiomatic expressions are mentally characterized and processed as lexical items. This means that when learners come across an idiomatic expression they interpret it literally and then mentally and figuratively if the literal meaning does not fit the context in which it is used. On the other hand, Nelson (1992) argues that language learners directly access the figurative denotation of the idiom whereas Liontas (2002) claims that language learners understand idiomatic expressions by primarily processing them literally and only then retrieve the figurative explanation. This means that literal processing of idioms must precede accessing the idiomatic interpretation. Other researchers (Sperber and Wilson, 1986, Gibbs, 1994; Recanati, 1995) propose simultaneous or parallel processing of idioms. In other words, when learners encounter an idiom string, both literal and figurative interpretations are activated in parallel (Vega-Moreno, 2001). This indicates that both the meaning of individual elements of an idiom along with the underlying conception as a holistic unit are activated. Mäntylä (2004) notes that one of the strategies the participants used to understand idioms is through resorting to the mother language and even when there is no clear equivalent in the native language, they select a figurative meaning in the native language even when only a single word is shared with the target language. Mäntylä adds that they rely on the literal meaning and pick the alternative that gives the literal meaning. In case none of these two strategies works, Mäntylä argues that they rely on pure guessing. This signifies that the transparency of selected idioms helps with the interpretation only when it is similar to the target language. Irujo (1986a) found that understanding the identical and comparable types of idioms is much better than idioms that are different from the ones in the native language. In addition, Irujo (ibid) noticed that though the participants used their mother language, they also used the strategies of the target language, i.e. they often used short, simple, and quite transparent best known idioms.

With regard to the teaching process of idioms, Sornig (1988) argues that idioms are so distinctive, thus no simple rule concerning them can be given. According to Sornig, teaching idioms should begin from the viewpoint of native speakers of the target language and how they themselves learn to understand idioms. Sornig claims that idioms are impressive if being taught in an effectively communicative and situational way. This way will help students remember them. In particular, he (ibid) proposes that teaching idioms should be carried out through categorizing them in relation to their communicative functions. This is mainly because idioms are used to make the communication very interesting in a very vivid way.

Irujo (1986) mentions different types of difficulties in learning idioms appropriately in a language learning context. Students often face difficulty whether to consider the idiomatic or the literal meaning of idioms in certain contexts. This confusion is caused by the fact that idioms in general vary in their level of formality and most idioms have literal 
counterparts. They also face difficulty recognizing the unfamiliar idioms (Mäntylä, 2004). Another problem is the lack of exposure to idioms which ranges from the omission of idioms in speech addressed particularly to nonnative speakers as not to cause confusion, and the entire ignorance of idiomatic expression in the target language materials and syllabi, besides the shortage of exercises designed to teach them. This indicates that students learn idioms out of context and in non-interactive situations (Mäntylä, 2004). This further means that they do have the chance to inquire about their actual meaning or even get any feedback on their own appropriate usage. Mäntylä (2004:174) believes that the context influences the interpretation of unfamiliar idioms in that it may limit the interpretation options and assist in excluding the clearly wrong ones.

\section{Statement of the problem}

Teaching idiom has not received adequate attention from foreign language teaching researchers (Vasiljevic, 2011; Tran, 2012). This could be attributed to the fact that very few Asian teachers are aware of the significant roles idioms play in developing communicative competence (Tran, 2013) or their ignorance of teaching them. Tran (2012) claims that they may experience difficulties in selecting the types of idioms to be taught to students and the appropriate teaching methods, or even illustrating the suitable use of idiomatic expressions according to context. Cain et al. (2005) claims that besides familiarity and transparency of idioms, context might facilitate the interpretation of figurative language. Idioms that are presented in texts are found to be easier to understand than those which are presented in isolation as the reader can extract or infer the appropriate sense of the target idiomatic expression.

Integrating idioms in the teaching and learning process of English has been found very essential and effective technique to help teachers and students support an innovative environment of learning and communication because it could be an effective way to provide students better conditions to improve their communicative skills (De Caro, 2009). A positive relationship between idiom comprehension and reading comprehension as well as academic achievement was found (Fusté-Herrmann, 2008). However, researchers (Rodriguez and Moreno, 2006; Zarei and Rahimi, 2012; Sparado, 2013; Zarei and Pour, 2013; Majuri, 2014 and Beloussova, 2015) claim that the acquisition of idiomatic expressions is one of the most outstanding challenges in context of teaching English as a foreign language. In addition and from the present researcher's personal experience, the motivation for conducting this study arises out of a deep and prolonged discontent which she has felt with teaching and learning of these idiomatic expressions in the Jordanian EFL context.

Sornig (1988) and Mäntylä's (2004) observe that even native speakers are doubtful about the use of idioms and make mistakes. This indicates that teaching idiomatic expressions to language learners might be very challenging. Studies have mainly focused on native speakers. English idioms and language learners have been ignored by researchers even though idioms are very significant and English is a dominant idiomatic language (Mäntylä 2004). Most idioms-related studies focus on the interlingual similarity (i.e. the equivalency between the literal translation and the meaning of the target idiom (Charteris-Black, 2002; Yoshikawa, 2008); interlingual familiarity (Charteris-Black, 2002; Boers, Demecheleer, and Eyckmans, 2004; Szczepaniak, 2006); the level of formality (Cooper, 1999); contextual inference (Cooper, 1999; Liontas, 2002a, 2002b, 2002c; Fuste-Hermann, 2008). However, very few studies concentrate on the strategies and difficulties students use and face when learning idioms (Saleh, and Zakaria, 2013; Angel, 2014; Manzoor, and Kiran, 2015).

Jordanian students encounter difficulties in learning English. Some of these are related to learning idiomatic expressions. They experience difficulties in using or understanding the meaning of several idioms that native speakers use in their daily written or spoken discourse even if they can speak English. This could be ascribed to the fact that the English language is full of idioms that baffle learners particularly the beginners. These difficulties usually result in poor language proficiency. The problem is that students are unaware of the severity of these difficulties. Thus, they simply ignore learning idioms. This could be due to the lack of knowledge of the appropriate strategies that help them learn idiomatic expressions in the target language. Numerous Jordanian studies shed light on the difficulties students encounter in translating idioms into Arabic (Hussein, Khanji, and Makhzoumi, 2000; Bataineh and Bataineh, 2002; Alrishan and Smadi, 2015). However, there has been no study that distinctly focuses on the strategies students use to learn idioms and the difficulties they face along with suggested solutions, though there have been major studies of idioms learning and teaching approaches (Lennon, 1998; Cooper, 1999; Levorato, Nesi, and Cacciari, 2004; Prodromou, 2003; Zyzik, 2011). Considering these issues, besides the limited research on the assessment of the idiomatic competence of Asian English language learners particularly Jordanian EFL learners, the present study hopes to fill the research gap.

Zyzik (2011: 414) calls for more research in this area claiming that "we are still in the initial stages of understanding the acquisition of idioms by non-native speakers". He also highlights the need for addressing idioms and idiom learning in the English language classroom. EFL learners' attitudes towards the target language are also significant because they play a vital role in learning and teaching that language (De Bot, Lowie and Verspoor, 2005). Thus, as in the present study, learner's perception of any essential part of learning language should not be ignored.

\section{Significance of the study}

A strong knowledge of idiomatic expressions will help students be better speakers since idioms give languages a natural, conversational and creative sense (De Caro, 2009; Majuri, 2014; Beloussova, 2015). The fact that idiomatic expressions are so often encountered in both spoken and written discourse necessitates using idiomatic expressions in and outside the classroom in order to assist students be competitive, enrich their vocabulary and enhance their way of speaking English. Therefore, understanding English idioms' meanings is expected to minimise difficulties Jordanian 
English learners may experience in understanding English native speakers' oral and written texts. On the other hand, learning idioms has been found very difficult to be achieved due to irrelevancy for implementing educational targets (De Caro, 2009). As a result, students often feel embarrassed and frustrated if they cannot use idioms in their writing or speaking or understand idioms others use.

Therefore, this study is an attempt to raise students' and teachers' awareness of the significance of idioms in their English learning. It is also hoped that the findings of the study will help teachers gain a deeper understanding of their students' idioms knowledge, preferred learning strategies as well as the difficulties they encounter and may impede their learning along with some suggested solutions. This in turn may lead to more appropriate teaching and enhanced idioms learning of the advanced learners. They may give these strategies and the difficult idioms more attention in the teaching and learning process. The students' awareness about the appropriate strategies for learning idioms will hopefully be raised when they are introduced to them. It is hoped that the results will provide those engaged in English language teaching and learning in Jordan with the suitable means for pre-empting and solving the problems and difficulties of teaching and learning idioms and idiomatic expressions. As for the courses composers, it is hoped that more attention will be given to the idioms that are a source of difficulty for students such as opaque, unfamiliar, and peculiar ones.

\section{Methodology}

\subsection{Research aims and questions}

The study aims to investigate students' perceptions of the importance of learning idioms, the most frequently used idioms learning strategies and the difficulties faced when trying to learn idioms. In addition, the study attempts to find out the most useful idioms learning strategies from the perception of English major students at the Hashemite University in Jordan. Thus, the study attempts to answer the following questions:

1. How do Jordanian students perceive learning idioms in English language?

2. According to the participants' perceptions, what problems, if any, Jordanian English major students face when learning idioms?

3. According to the participants' perceptions, what are the most useful and frequently used idioms learning strategies?

4. Are there any in the performance of the idioms-based test in respect to the university academic year?

\subsection{Research methodology and design}

This study is a survey research type. It is empirical with some theoretical insights concerning teaching English as a foreign language. Mixed methodology was adopted to carry out the present study. A test was developed to test students' perception and knowledge of some idiomatic expressions and find out if there is a difference between university students across different academic levels. The test was mainly used to give a clear idea about the student's idiomatic competency. It could be regarded as the starting point as it gives teachers, curricula developers and policymakers as well as researchers some information about what students know, so that they also have an awareness of what they need to learn, review and research. It is particularly used because it exclusively focuses on the students' proficiency in the target language (i.e. Knowledge and mastery of idioms and idiomatic expressions). Afterwards, the results were graded, and inferences made about the participants' performance and any differences found between them. This in turn gives the teachers and researchers information about what the student's level and what they need to learn (Elgobshawi, 2012). It consisted of a list of idioms to define, some others to use properly according to context, and the third section requires students to give of the idiomatic expressions they know and their meanings. In order to get as much information as we can, another question was added to allow student provide any comments they had about teaching and learning idioms at university. This question helped us in the interpretation of the results.

A questionnaire was developed and modified based on a review of the existing literature to investigate the strategies they use to learn idioms, the difficulties they face, and some suggested solutions. The questionnaire was of Likert type scale. EFL learners' perceptions of idioms were elicited on a 5-point Likert scale: $1=$ strongly disagree; $2=$ disagree; $3=$ undetermined; 4 = agree; 5 = strongly agree. EFL learners' strategies of learning idioms were elicited on a 5-point Likert scale: $1=$ never; $2=$ seldom; 3 sometimes; $4=$ frequently; $5=$ always. SPSS (statistical package for social sciences) software was used to analyze data in the form of descriptive statistics (primarily frequencies, mean, percentage and standard deviation to identify students' opinion about different strategies and difficulties for learning idioms. The questionnaire format was also used due to different advantage: gathering a large amount of information within a short time immediately without pressure, the direct administration both individually or in groups) and informing directly about the students' background, attitude(s), preferences, opinions, learning styles and strategies (Elgobshawi, 2012) and providing results that are easily quantified and analyzed (Dornyei, 2003; Gillham, 2007).

\subsection{Participants of the study}

The participants of the study were selected purposefully. They were all BA English language learners at the Hashemite University in Jordan. The total number of the students who participated in the study was 150 . Hindered of them participated in the questionnaire and fifty participants took part in the exam. All of them were full-time students aged around 20 and 24 years old. This research was carried out during the second summer semester of the academic year 2014-2015. The questionnaire and the test were administered during class time in courses (i.e. essay writing and listening comprehension) selected purposively to ensure comprehensive coverage of the four academic levels. 
Participation was on a voluntary basis. The participants also signed an informed consent form illustrating the purpose of the study, the instruments and the researchers' contact information.

\subsection{Validity and reliability of the research instruments}

In order to establish the validity of the research instruments, the test and questionnaire were sent along with a brief about the study to 5 Jordanian EFL professors at the Hashemite University to ensure that the items are clear and appropriate for aims of the study and for the students' level of language proficiency. Their comments and suggestions were taken into consideration. For example, some very difficult idioms were deleted from the test and another question has been added to provide the most known idioms and fill in idioms the suitable context. In addition, instead of five alternatives, I had only four alternatives with only one correct answer. The questionnaire was also modified where the statements related to opinions are grouped together and those related to action are grouped together. The questionnaire functioned very well in the sense that the participants did not have any problems with the questions (i.e. there were frequent and less frequent idioms) and were able to fill it within the appropriate time. To establish the reliability of the research instruments, they were piloted twice to 20 students, who were excluded from participating in the main study at both universities under investigation. Afterwards, it was modified accordingly. The results were examined carefully by the present researchers.

\section{Results and discussion}

\subsection{How do Jordanian students perceive learning idioms in English language?}

6.2 According to the participants' perceptions, what problems, if any, Jordanian English major students face when learning idioms?

Table 1 (see Appendix C 1) shows the frequencies, percentages, mean and standard deviation of the participants' responses regarding their perception and difficulties of learning English idioms and idiomatic expressions. As shown in this table, the majority of the participants $(\% 68)$ were less aware of the significance and advantages of learning idioms. Most of my students did not find themselves good at neither learning nor using idioms. This could be attributed to the fact that the majority of them find English idiomatic expressions very difficult to learn (\%70) and use (\%68). The difficulty could stem, as claimed by Hussein, Khanji and Makhzoomy (2011), from the fact that idioms are arbitrary and non-literal. It could be explained by the result we found that a great number of students did not have a dictionary specifically for English idioms and idiomatic expressions. It could also be interpreted by the fact teaching idioms is not given at university in a course specifically designed for that rather they might be explained if being come across during other courses such as sociolinguistics, pragmatics, reading and listening comprehension etc. This result supports other researches' (Saleh, and Zakaria, 2013; Al-Kadi, 2015) results that the majority of Arab English language learners face hardship in acquiring, understanding and using idioms. However, it is very clear from the table that there is a contradiction between the students' very poor idiomatic competence (i.e. limited knowledge of idiomatic expressions) and their overwhelming desire to learn and use them as part of their process of learning English language. This indicates that the students do not have any prior good knowledge about idioms in general. This could also mean that the students had not been trained to learn how to comprehend or use idioms. The knowledge they had of very few idiomatic expressions resulted unintentionally: i.e. when they came cross them during reading or listening and they had time to look them up in the dictionary. Some of them were personally encouraged to investigate further their meaning to facilitate the target task. This result does not match the fact that recognizing, producing and using idiomatic language is a part of the descriptions of proficiency levels, i.e. an important level of language proficiency which all students should master by the end of their secondary education (Framework curriculum for senior secondary school 2003).

The results revealed that Jordanian university students encountered difficulties in understanding and using English idioms even though most of them were advanced fourth and third year university students of English. The test showed poor competency in understanding, producing and using different idiomatic expressions in different contexts. The majority of the students could not understand the meaning of the provided list of idioms, use them correctly or even provide some other examples and their interpretations. They did not even know how to use them correctly in their process of learning English. It seemed that students felt embarrassed and frustrated because they could not understand the idioms that they repeatedly encountered in both spoken and written discourse.

The students' poor competency of idioms and the difficulties they face when learning idioms might also be attributed to the lack of time because they did not have enough time to fulfill all their goals, to fact that they are not part of the courses' syllabi (\%98), and the lack of cultural background behind the idioms (\%88). This indicates that though integrating idioms is viewed as an effective technique implemented to promote an innovative environment of communication, facilitate needs and challenge students' learning process, it is viewed as irrelevant or necessary for executing educational goals. They are mostly neglected both by their teachers and the target courses in process of teaching English as the majority could not decide if they were taught well in the classroom or not (\%69). This means that students were deprived from the opportunity to learn idioms in classrooms and they were not even asked to learn them even outside their classrooms. Such difficulties could also be ascribed to other reasons postulated by Irujo (1986) and Pimenova (2011) such as the intentional omission of idioms or the use of simple, concrete, everyday idiom while conversing with nonnative speakers, the unknown vocabulary and unfamiliar idioms, cultural differences (i.e. no oneone equivalent idioms across cultures), lack of the extensive context of a given idiom as well as lack of experience dealing with idioms. Overall, it can be concluded that the findings of the present study confirm other researchers' findings Nakhallah (2010), Hussein, Khanji and Makhzoomy (2011), Thawabteh (2011), Chen and Lai (2013) that the 
difficulty of idiom stems from their syntactic, semantic and pragmatic features. In other words, EFL learners may find it really difficult to recognize idioms' structures, comprehend their meanings and convert their meanings (translating) into their native language. In addition to these reasons, Rizq (2015) adds that the adopted methods of teaching idioms also contribute to their difficulty. The results indicate that students should be made aware of the fact that improving their idiomatic knowledge could help them express their views in a short, beautiful and flowery language and sound more proficient. This further indicates that they are in need of improving their communicative skills through idiom-based learning. The result is consistent with some studies (Elgobshawi, 2012) which show that idioms is neglected in the teaching and learning process of English and should be given more attention.

6.3 According to the participants' perceptions, what are the most useful and frequently used idioms learning strategies?

Table 2 (see Appendix C 2) shows the frequencies, percentages, mean and standard deviation of the participants' responses regarding their strategies they follow for learning English idioms and idiomatic expressions.

As shown in the Table 2, a great number of students resorts to a variety of strategies for comprehending and learning idioms as they do find it easy to predict the meaning of the idioms. This implies that different learners might make a selection of a wide variety of idioms learning strategies. It is apparent that the majority of the students mostly rely on context in order to guess the meaning of idiomatic expressions they come across. The results revealed that inferring from context in comparison with other strategies was confirmed to be effective to a significant degree by (\% 69) of the students. This highlights the importance of teaching and learning idioms in context as it helps in guessing the meaning of the target idioms by limiting the unfamiliar figurative language. Interpretations of the meaning of target idiomatic expressions are not made until there is enough evidence to support a possible interpretation from contextual clues. This indicates that teachers should equip learners with appropriate skills to utilize the context in guessing the figurative meaning of idioms.

The result supports other researchers' results (Irujo 1986a; Rohani, et.al. 2012; Asl, 2013) about the importance of including the context in teaching and learning idioms in general. This finding corroborates the finding of Asl (2013) that the presence of context does considerably affect the learning and understanding of idioms. It is also consistent with Tran's (2012) argument that teaching idioms in context could generally help minimise the difficulties students face in understanding the meaning of certain decontextulaised idioms. Thus, it could be argued that the more authentic the context is the better it supports the educational process. Therefore, it could be argued that this finding is in line with Ortony et al.'s (1978:474) suggestion that “processing the context activates adequate appropriate schemata to enable an idiomatic expression to be arrived at quite readily" since learners employ "an already constructed representation of what has gone before (the context) as a conceptual framework for interpreting a target sentence, or any other linguistic unit" (467). Consequently, as Nation (2001) recommends that idioms can be added to the vocabularies being acquired through integrating them in dialogues and stories that are designed to complement regular learning materials as they are a good chance for students to practice with basic speaking skills in context. Using authentic texts from newspapers, magazines, internet could be a significant way to introduce different idiomatic expressions to students. Watching live programs or videos sketches can also provide learners with situations to learn continually learn idiomatic expressions in various situations and contexts. This finding substantiates Irujo's (1986b) claim that idiomatic expressions are best learned in interactive situations such as TV language which usually contain idioms because the clues in the context could easily help learners remember the meaning of the idioms vividly. The present researcher supports Wu's (2008) and Al-kadi's (2015) proposition of designing various collaborative activities where idiom could be taught integrating the four language skills such as teaching idioms in story contexts, group discussion, dialogue writing and role-play. Such activities will be a good chance for EFL students to use English idioms to interact with their peers and share fun in learning. Moreover, having the opportunity to travel abroad and being in regular contact with native speakers help language learners feel better in developing their idiomatic expressions repertoire, as through the personal experience, the present researcher noticed that the English native speakers frequently use idioms in their conversation. This enables learners to consult and discuss the meaning of the idioms encountered in interactive conditions whenever necessary. The present study lends supports to Sridhar and Karunakaran's (2013) findings in that teaching idiomatic expressions should be treated as new items and students should be encouraged the guess their meaning from situation and context.

The participants stated that the easiest and the most understandable idioms are those which have some sort of an equivalent meaning in Jordanian Arabic such as " give the green light", "a piece of cake" , "Can’t judge a book from its cover", "made up your mind", " take the hat off" were easier to learn and memories. This might indicate that one can understand idioms very easy if they have a good knowledge of idioms in their culture and mother language and if there is a similarity between both the mother and target language. This result affirms the importance of the concept of culture in teaching and learning culture. This result corroborates the findings of Liu (2008) and Chen and Lai (2013) that students increase frequencies of leaning and using not only popular idiomatic expressions but also L2 expressions whose conceptual metaphors also exist in the native language more often than those expressions whose conceptual metaphors are exclusive in foreign or second language. This further designates that teacher course and syllabus designers should highly consider the fact that students find it easy to learn idioms which have conceptualization in both their first and second language. Based on the results, it seems that teachers should try to highlight a connection if found between the learners' first and target language because they rely on their first-hand knowledge and experience of idioms anyway when trying to understand them in a foreign language. They should make use of the learners' first language since such good knowledge might guide them in selecting the types of idioms to be taught first and then gradually into the difficult ones. This result is in agreement with Moein and Khosravi s' (2014) finding that idioms are mostly context- 
dependent and vary cross languages and cultures culture. It also lends support to Violetta's (2015) argument that idioms' origins may be difficult to trace if they derive from domains that are not prevalent in learners' culture. This result highlights the importance of integrating cultural courses in teaching language as they affect the capacity of learners' understanding and interpretation of the idiomatic language.

The results also showed that the more transparent the idiom is the easier the students could recognize. This means that transparency has a great impact and it would make sense to teach idioms that are very clear and easy to understand and use. This result indicates that literal meanings of idioms are activated more than the figurative. This implies that the idioms figurative connotation is not activated as quickly as the literal one and the literal figurative meaning always comes prior to retrieving the figurative meaning in processing idioms. This further indicates that there is no point in teaching infrequent, highly colloquial idioms that include complicated vocabulary to EFL learners. It has also been revealed that the best way to teach idioms is to deal with them as new items which students should be encouraged to guess their meaning of the target idioms from context rather than simply ignoring them. It is worth mentioning that idiom comprehension can definitely be increased if students show interest in using language inside and outside classrooms either through reading, speaking, listening or writing. The greater interest in learning idioms the better the level of language proficiency. This result lends support to previous studies (e.g. Irujo 1986a, Nippold and Rudzinski 1993, Nippold and Taylor, 1995, Mäntylä 2004) which indicate that familiarity, transparency and equivalence in mother tongue could greatly facilitate idiom recognition and comprehension.

As shown in the table, the other strategies the students use are learning idiomatic expressions through reading different types of texts, and various media means. This assert the point that teacher should encourage students to invest media and reading different books in learning new idiomatic expressions. Group discussion is the strategy that is sometimes used by the learners with a percentage of (\%56) followed by code breaking of the meaning of the individual parts of idioms to guess the meaning of their constituent words via activating mental lexicon with the percentage of (53). It appears that retelling and paraphrasing of idioms is very seldom used by $(\% 55)$ percentage of students. The findings are consistent with Guduru's (2012: 488) finding that the most useful strategies for learning and teaching English idioms are learning idioms through conversations, group discussion, memorization and analysing the keyword besides using idiom books and notebooks.

The high percentage of those ignoring learning the idioms if they encounter unknown and difficult idioms means that teachers should not ignore those complicated one, rather they should motivate and equip their students with specific strategies to facilitates understanding them.

The most prominent result is that the majority of students appeared to be interested to be taught more specific strategies and equipped with skills and processes necessary to create meaning from idiomatic text to facilitate learning idioms in foreign language. The results further indicate that students are in need of getting knowledge about idioms and being instructed on how to recognize and use the idiomatic interpretations appropriately.

\subsection{Are there any differences in the performance of the idioms-based test in respect to the university academic year?}

The results of the test showed a difference in the idiomatic knowledge between students of different academic years. The results showed that four year and third students chose more correct answers in the idiom test than first and second year students. The marks of the junior and senior students ranged from 9-12/20 compared to the freshman and sophomore whose marks ranged from 0-6/20. They do not have specialized idioms course books during English lessons rather they studied more literature books which means they are required to read more. This further indicates a good connection between learning idioms and reading more books, i.e. those who read more could do much better than those who do not. This means that teachers should encourage students to read and provide them with more authentic reading materials. The results suggest that the number of the course books they have read and the number of the years they studied could have a significant impact on their idiomatic knowledge. This result is in line with Aljabri (2013) who found a great difference between students across different academic years.

Due to their significance and based on the results of the study, idiomatic expressions require special attention in language programs to help students improve their communicative skills. Thus, attention should be directed to their importance and raise the awareness of their position in English language. Since it is very important that language learners use idioms all the time, teachers have to lead their students to become competitive learners through constructing certain types of activities effectively to train them and assure the success of using idioms in and outside the classroom. Idiomatic expressions should be taught to students, and specifically the most common ones that are often used since they are so important in the process of communication. The sort of activities and how they are constructed by teachers in the classroom seem to be one of the most significant aspects that assist using idioms in and outside the classroom successfully. In accordance with Irujo (1986 b), teachers should propose certain exercises on idioms because materials often poorly support teaching them. In sum, the findings of the current study provide support to the fact that idioms can be used frequently in daily situations, and therefore they deserve to be a part of syllabus of the target language. I propose to incorporate teaching idiomatic expressions in each curriculum whether linguistics or literature course in addition to certain activities in order to help students improve their communicative skill.

\section{Conclusion and recommendations}

A strong knowledge of idioms will help students be better speakers. The high number of idioms and their high frequency in discourse are important aspects of increasing their vocabulary repertoire, improving their communicative skill and facilitating understanding conversations and written texts. However, students encounter some problems and 
difficulties when learning idioms. Based on this fact, the present researcher argues that figurative idiomatic language should receive adequate attention in the teaching and learning process. Attempts to enhance student communicative practice including the use of idioms should be considered and increased. Idioms should not be ignored in the language teaching process. Rather, the use of specific idioms should be included in the teaching process as a useful strategy to help the learner improve their communicative skill. For example, this language component is a way to help student understand native English speakers' speech, movies, and songs and increase their lexicon. This is because when students know how to use idioms, they feel better and they can trust on themselves since they are able to understand what English speakers want to express by using idioms. Workshops can be designed to help students use idioms and improve their speaking skills through pressing them useful idioms with understandable examples and interactive situations where students can be encouraged to analyze the correct use of idioms. However, teachers should be aware of the criteria according to which they select idioms to be taught. Based on the result, students learn the most frequent, familiar, transparent, simplest ones and the most important are those which have first language equivalents. Teachers should consider that fact that idiomatic expressions that are culturally-bound are easy to learn and those have a figurative meaning that differ from the literal meanings of its composing words within the expression are difficult to learn.

In addition, they should be taught in a way that is appropriate and interesting to the students' academic levels and stage of learning. Students should be also equipped with certain strategies and encouraged to learn idiomatic expressions as they appeared to be afraid of using them due to their figurative interpretations. In such way, language learners can feel confident acquiring and using idioms inside and outside the classroom. Inference from the semantic similarity of certain idioms and idiomatic expressions the mother tongue and second or foreign language, inference of the meaning of the target idioms from context, inference of the meaning of the target idioms from the familiarity of the idiomatic expression should be considered by teachers and students in order to get the correct meaning of the intended idioms.

Context plays a crucial role in understanding idioms. Idioms have relation with context and their meanings are found to be easier to figure out when used in context. This implies that idioms should be taught through context, acting, dialogue, and reading. It is worth mentioning that extended reading texts rather than sentences or paragraphs should be regarded for teaching idioms in order to train students to use the inference (i.e. forward and backward textual strategies) based on the context. In these ways, students can be taught how to negotiate the figurative meaning of the target idiomatic expressions to avoid misunderstanding. It is evident that lack of idioms knowledge could have an academic impact on the learners' overall academic performance. The negligence of idioms in language curricula and lack of motivation from the teachers' side led to their negligence in the context of EFL learning. Thus, it is necessary for teachers and students to pay particular attention to teaching idioms in a suitable environment. In addition, teachers must be aware of the significance and advantages of utilizing idioms and integrating them in the development of the English language skills. They should also be motivated to teach them. Even if idioms and idiomatic expressions are not the main focus in teaching language, occasional exercises would definitely enhance their understanding. Teachers and teaching materials should also encourage students and provide them with practice on certain idioms and in their spare time.

It would be very interesting to carry out further research on idioms difficulties and strategies of learning using huge samples from different universities and academic levels to support the present study's findings. A study could be carried out to investigate the relation between frequency of idiomatic expression, their familiarity to non-native Jordanian English learners and learners' recognition of such idioms compared to infrequent idioms. Studying the variation between the same idioms' literal and the figurative meaning according to context is worth investigated. It is intriguing to examine frequently used idiomatic expressions by native English speakers as to include them in the teaching materials. A study may be carried out to examine the actual use of these strategies in test; i.e. asking them about the strategies they actually used in working out the test items. A theoretical study could be conducted to examine the relation between idioms and speech acts particularly illocutionary speech acts.

\section{Acknowledgement}

We would like to express gratitude to all professors who generously provided constructive comments on the preliminary version of this paper. We would like to acknowledge the help and support I got from the students who participated in the study. They enthusiastically answered the idiom tests and replied to the questionnaire. We are also thankful to all the authors of the relevant works as they provided the background of the present study. We are equally grateful to the anonymous reviewers for their valuable comments and suggestions.

\section{References}

Ababneh, S. and Al- Momani, M. (2011). The effect of a vocational instructional program on vocational students' English language proficiency. International Journal of Vocational Education and Training, 19, 53-66.

Aljabri, S. (2013). EFL students' judgment of English idiom familiarity and Transparency. Journal of Language Teaching and Research, 4(4), 662-669.

Alrishan A. and Smadi, O. (2015). Strategies used by Jordanian EFL university graduate students in translating idioms into Arabic. Journal of Education and Practice, 6 (6), 45-55.

Al-Kadi, A. (2015). Towards Idiomatic Competence of Yemeni EFL Undergraduates. Journal of Language Teaching and Research, 6(3), 513-523.

Asl, F. M (2013). The impact of context on learning idioms in EFL classes. MEXTESOL Journal, 37(1), 1-12. 
Bataineh, R., and Bataineh, R. (2002). The difficulties Jordanian graduate learners of English as a second language face when translating English idioms into Arabic. RASK: internationalt tidsskrift for sprog og kommunikation 16, 33-83.

Beloussova, V. (2015). Idiom learning materials for Estonian Secondary School students. Unpublished MA thesis. Estonia, University of Tartu.

Brenner, G. (2011). Webster's new world American idioms handbook. New York: Houghton Mifflin Harcourt.

British Council. (2012). IELTS speaking band descriptors (public version). Retrieved January 15, 2016, from http://www.britishcouncil.org/srilanka-exams-ielts-descriptor-speaking.pdf

Cain, K. and Oakhill, J. \& Lemmon, K. (2005). The relation between children's reading comprehension level and their comprehension of idioms. Journal of Experimental Child Psychology, 90, 65-87.

Carkin, S. (2005). English for Academic Purposes. In Hinkel E. (ed). A Handbook of Research in Second Language Teaching and Learning, 85-98. Lawrence Elbaum Associates, Inc. New Jersey

Celce-Murcia, M. (2008). Rethinking the role of communicative competence in language teaching. In E. Alcón Soler \& P. Safont Jordà (eds.), Intercultural language use and language learning, 41-57. Dordrecht, The Netherlands: Springer.

Chen, Y. and Lai, H. (2013). Teaching English idioms as metaphors through cognitive-oriented methods: A case in an

EFL writing class. English Language Teaching, 6(6), 13-20.

Conklin, K. \& Schmitt, N. (2008). Formulaic sequences: Are they processed more quickly than nonformulaic language by native and nonnative speakers? Applied Linguistics, 29(1), 72-89.

Cooper, T. C. (1999). Processing of idioms by L2 learners of English. TESOL Quarterly, 33(2), $233-262$. http://dx.doi.org/10.2307/3587719.

Crystal, D. (1991). A dictionary of Linguistics and Phonetics. 3rd ed. Oxford. Blackwell press.

De Bot, K., Lowie, W., and Verspoor, M. (2005). Second Language Acquisition, an advanced resource book. London: Routledge.

De Caro, E. E. R. (2009). The advantages and importance of learning and using idioms in English. Cuademos de Linguistica Hispanica, 14, 121-136.

Dornyei, Z. (2003). Questionnaire in second language research: Construction, administration, and processing. New

York, NY: Lawrence Erlbaum.

Elgobshawi, O. (2012). An investigation into difficulties of understanding and using English idioms facing Sudanese students majoring in English language. Unpublished Ph.D. thesis. Sudan: Sudan University of Science and Technology. Ellis, N. (1997). Vocabulary acquisition: Word structure, collocation, word- class, and meaning, in Schmitt, N. and McMarthy, M. (Eds.): Vocabulary, Description, Acquisition And Pedagogy, Cambridge: CUP, 122-139.

Fusté-Herrmann,B. (2008). Idiom comprehension in bilingual and monolingual adolescents. Unpublished $\mathrm{PhD}$ thesis. Florida, University of South Florida.

Gillham, B. (2007). Developing a questionnaire (2nd ed.). New York, NY: Continuum.

Glucksberg, S. (2001). Understanding figurative language. From metaphors to idioms, Oxford, OUP.

Guduru, R. (2012). Learning academic idioms: Some useful techniques for beginner learners. Language in India:

Strength for

Today and Bright Hope for Tomorrow, 12(2), 494-585.

Hussein, R., Khanji, R., and Makhzoumi, K. (2000). Idioms: Transfer or what?. Language and Translation Journal,12,23-34.

Hussein, R. Khanji, R. \& Makhzoomy, K. (2011). The Acquisition of idioms: Transfer or what? Journal of King Saud University, 12, 23-34.

Irujo, S. (1986). Don't put your leg in your mouth: Transfer in the acquisition of idioms in a second language. TESOL Quarterly, 20(2), 287-301.

Kellerman, E. (1986). An eye for an eye: Crosslinguistic constraints on the development of the L2 lexicon. In E. Kellerman \& M. Sharwood-Smith (eds.). Crosslinguistic influence in second language acquisition, 35-48. Oxford Pergamon Press.

Lennon, P. (1998). Approaches to the teaching of idiomatic language. International Review of Applied Linguistics in Language Teaching, 36(1), 11-30.

Mäntylä, K. (2004). Idioms and language users: The effect of the characteristics of idioms on their recognition and interpretation by native and non-native speakers of English [online]. University of Jyväskylä. http://selene.lib.jyu.fi:8080/vaitos/studies/studhum/9513917177. Retrieved on February, 16 (2016).

Manzoor, S. and Kiran, S. (2015). Impact of strategies in handling the difficulties of idioms. International Journal of Sciences: Basic and Applied Research, 21(2), 224-234.

Nakhallah, A. (2010). Difficulties and problems facing English students at QOU in the translation process from English to Arabic and their solutions. Al-Quds Open University. Retrieved May.10, 2016 from

http://www.qou.edu/english/conferences/firstNationalConference/pdfFiles/ahmadMaher.pdf.

Nation I.S.P. ( 2001). Learning vocabulary in another language. Cambridge: CUP.

Ortony, A., Schallert, D. L., Reynolds, R.E., and Antos, S. (1978). Interpreting metaphors and idioms:

Some effects of context on comprehension. Journal of Verbal Learning and Verbal Behavior, 17, 465-477.

Pimenova, N. (2011). Idiom comprehension strategies used by English and Russian language learners in a think-aloud study. Unpublished Ph.D. thesis, West Lafayette, Indiana, Purdue University. 


Prodromou, L. (2003). Idiomaticity and the non-native speaker. English Today, 19(2), $42-48$.
http://dx.doi.org/10.1017/S0266078403002086 .

Qualls, C. D., Treaster, B., Blood, G. W., and Hammer, C. S. (2003). Lexicalization of idioms in urban fifth graders: A reaction time study. Journal of Communication Disorders, 36(4), 245-261.

Recanati, F. (1995). The alleged priority of literal interpretation. Cognitive Science, 19, 207-232.

Rizq, W. (2015). Teaching English idioms to L2 learners: ESL teachers' perspective. Unpublished MA thesis. St. Cloud State University/

Roberto de Caro, E. E. (2009). The advantages and importance of learning and using idioms in English. Cuadernos de Lingüística Hispánica, 14, 121-136.

Rodríguez, I. L., \& Moreno, E. M. G. (2009). Teaching idiomatic expressions to learners of EFL through a corpus based on Disney movies. In A survey of corpus-based research [Recurso electrónico] (pp. 240-253).

Rohani, G., Ketabi S. and Tavakol. M (2012). The Effect of Context on the EFL Learners' Idiom Processing Strategies. English Language Teaching, 5( 9):104-114.

Saleh, N. and Zakaria, N. (2013). Investigating the difficulties faced in understanding, and strategies used in processing, English idioms by the Libyan students. International Journal of English Language and Translation Studies (IJ-ELTS), 1(2), 69-90.

Sparado, K. (2013). Maturational constraints on lexical acquisition in a second language. In Gisela Granena and Mike Long (eds). Sensitive Periods, Language Aptitude, and Ultimate L2 Attainment, 43-68. Amsterdam/Phildelphia: John Benjamins.

Sperber, D. and Wilson, D. (1986). Relevance: Communication and Cognition. Blackwell, Oxford and Harvard UP, Cambridge MA.

Sridhar,M. and Karunakaran,T (2013). Idioms and importance of teaching idioms to ESL Students: A Study on Teacher Beliefs. Asian Journal of Humanities and Social Sciences (AJHSS), 1(1), 110-122.

Majuri, T. (2014). Idioms and L2 learners: The Effect of L1, transparency and frequency on idiom comprehension by Finnish and Italian learners of English. Unpublished MA thesis. Finland, University of Turku

Moein, B. and Khosravi, R. (2014). The role of cross-linguistic experience on English idiom and proverb comprehension: A case of Iranian Turkish learners of English as a foreign and third language. Theory and Practice in Language Studies, 4 (5), 1017-1025.

Thawabteh, M. (2011). Linguistic, cultural, and technical problems in English-Arabic subtitling. Journal of Translation and Interpretation, 5, 1, 24-44.

Tran, H. Q. (2012). An explorative study of idiom teaching for pre -service teachers of English, English Language Teaching, 5(12), 76-86.

Tran, H. (2013). Figurative idiomatic competence: An analysis of EFL learners in Vietnam. Language Education in Asia, 4(1), 23-38

Trosborg, A. (1985). Metaphoric productions and preferences in second language learners. Parpotté, W. and Dirven, R. (eds.): The Ubiquity of metaphor. Metaphor in language and thought, Amsterdam/Philadelphia: John Benjamins, 525557.

Vasiljevic, Z. (2011). Using conceptual metaphors and L1 definitions in teaching idioms to nonnative speakers. The Journal of Asia TEFL, 8(3), 135-160. http://dx.doi.org/10.1177/1362168811412025.

Vega-Moreno, Rosa Elena, (2001). Representing and Processing Idioms. UCL Working Papers in Linguistics, 13, 73107.Yorio, C. A. (1989). Idiomaticity as an indicator of second language proficiency. In Hyltenstam, K. \& L. K. Obler (eds.), Bilingualism across the lifespan, Cambridge: Cambridge University Press.

Violetta b. (2015). Idiom learning materials for Estonian Secondary School students. Unpublished MA thesis. Estonia. University of Tartu

Zarei, A. and Pour, V. (2013). Language learning strategies as predictors of L2 idioms comprehension. International Journal of Language Learning and Applied Linguistics World, 4(2), 330-313.

Zarei, A., \& Rahimi, N. (2012). Idioms: Etymology, contextual pragmatic clues and lexical knowledge in focus. Germany: Lambert academic publishing.

Zyzik, E. (2011). Second language idiom learning: The effects of lexical knowledge and pedagogical sequencing. Language Teaching Research, 15(4), 413-433. 
Appendix A. The Questionnaire

1. Academic year.

2. Specialization

3. Gender.

\begin{tabular}{|c|c|c|c|c|c|}
\hline Perception of learning English idioms & 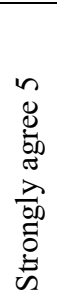 & 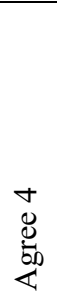 & 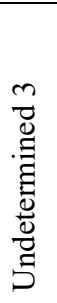 & 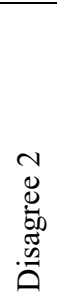 & 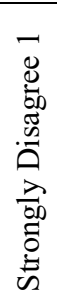 \\
\hline 1. Learning idioms is an important part of learning English language & & & & & \\
\hline 2. I'm good at learning idioms. & & & & & \\
\hline 3. I like to use idioms in speaking and writing English language. & & & & & \\
\hline 4. I want to learn a variety of idioms as part of learning English language. & & & & & \\
\hline 5. Idioms are easy to learn. & & & & & \\
\hline 6. Idioms are easy to use. & & & & & \\
\hline 7. I have a dictionary specifically for idioms. & & & & & \\
\hline 8. I'm good at using idioms. & & & & & \\
\hline Difficulties & & & & & \\
\hline $\begin{array}{l}\text { 1. Idioms are difficult to understand because of the lack of cultural } \\
\text { background behind the idioms. }\end{array}$ & & & & & \\
\hline 2. Idioms are difficult because they are not part of the courses' syllabi. & & & & & \\
\hline 3. Idioms are difficult because they are not taught well in class. & & & & & \\
\hline $\begin{array}{l}\text { 4. Idioms are difficult because the cultural courses I studied were not } \\
\text { efficient. }\end{array}$ & & & & & \\
\hline Some suggested solution for these problems & & & & & \\
\hline Frequency of strategies for learning English idioms & 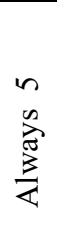 & 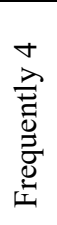 & 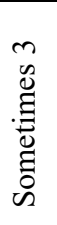 & $\begin{array}{l}\text { N } \\
\Xi \\
\frac{0}{0} \\
\tilde{D}\end{array}$ & $\begin{array}{l}\overrightarrow{\bar{d}} \\
\bar{d} \\
\bar{z}\end{array}$ \\
\hline 1. I can predict the meaning of idioms. & & & & & \\
\hline $\begin{array}{l}\text { 2. I use verbal (textual or audio) and visual } \\
\text { information help to activate my knowledge of idioms }\end{array}$ & & & & & \\
\hline $\begin{array}{l}\text { 3. I guess the overall meaning of an idiom through breaking it into parts } \\
\text { and guessing the meaning of their constituent words. }\end{array}$ & & & & & \\
\hline 4. I can figure out an idiom from an equivalent one in my language. & & & & & \\
\hline $\begin{array}{l}\text { 5. I translate the literal meaning into my L1 (first language) to understand } \\
\text { idioms. }\end{array}$ & & & & & \\
\hline 6. I learn idioms through group discussion & & & & & \\
\hline 7. I learn idioms through retelling and paraphrasing. & & & & & \\
\hline 8.I learn idioms with clear literal meaning & & & & & \\
\hline 9. I learn idioms with rich illustration.9 & & & & & \\
\hline 10. When facing a difficult idiom, I ignore it. & & & & & \\
\hline 11. I learn only familiar idioms with familiar vocabulary. & & & & & \\
\hline $\begin{array}{l}\text { 12. I use many different strategies when } \\
\text { Learning idioms. }\end{array}$ & & & & & \\
\hline 13. I learn idioms which have multi-word combination & & & & & \\
\hline 14. I learn idioms used in used different media. & & & & & \\
\hline 15. I learn idioms through different readings. & & & & & \\
\hline 16. I up look unknown idioms in the dictionary. & & & & & \\
\hline 17. I guess the meaning of idioms through the context. & & & & & \\
\hline $\begin{array}{l}\text { 18. I need to know what other strategies I can use to make better sense of } \\
\text { idioms. }\end{array}$ & & & & & \\
\hline
\end{tabular}


Appendix B. English Idioms Test

A. Academic year.

B. Specialization

C. Gender.

1. list 5 idioms you know and their meanings (5 MARKS).

$1 . \quad 2.4$. 4.

2. Fill in the following blanks with the suitable words (10 MARKS).

1. Ruba and I are as different as ........ and cheese.

a) Biscuits

b) Chalk

c) Ham

d) Jam

3. My brother advised me to study law, but I had made up my to become an Archaeologist, instead .

a) Heart

b) Head

c) Brain

d) Mind

4. You haven't been studying much recently and you'd better Literature.

a) thread your way through

b) meet your Waterloo

c) pull your socks up

d) change your spots

5. Don't throw that old Grammar textbook away. It will exam.

a) turn

b) find

c) come

d) give

6. Mena has been in Sarah's since he called her a fat duck.

a) bad letters

b) bad books

c) bad records

c) bad papers

7. The school head' resignation came like a bolt from the . None of the staff had anticipated it.

a) green

b) red

c) black

d) blue

8. His directness seemed designed to throw Michael off balance means

a) make someone change their opinion

b) make someone feel angry

c) suddenly confuse or surprise someone

9. The Kuwaiti football team never wins. So I wouldn't put my in handy when your brother is studying for Tawjihi if you want to pass the American English

a) shoes

b) shirt

c) jacket

d) hat

10. If you ......... you work very hard.

a) work to the winds

b) work like a new leaf

c) work your fingers to the bone

d) work until you are blue and black.

10. The kids are really getting in my

a) hair

b) nerves

c) mouth

d) books

11. Complete the following idiomatic expression with the suitable word(s) (5 MARKS).

(a). A thing that is very easy to do: a piece of

(b). Not what I like or am interested in: Not my cup...............

(c). To be able to think and react to things very quickly and effectively without any preparation: Thinking

on...FEET........................

(d). In a way that was not expected, unexpectedly: Out of......BLUE

(e) Used to say that something proves something: It goes...

12. Please provide any comments about teaching and learning idioms at university. 
Appendix C. Results

Appendix C 1: The frequencies, percentages, mean and standard deviation of the participants' responses regarding their perception and difficulties of learning English idioms and idiomatic expressions

Table 1. The frequencies, percentages, mean and standard deviation of the participants' responses regarding their perception and difficulties of learning English idioms and idiomatic expressions

\begin{tabular}{|c|c|c|c|c|c|}
\hline $\begin{array}{l}\text { Perception of learning English } \\
\text { idioms }\end{array}$ & & Frequency & Percent & Mean & $\begin{array}{l}\text { Standard } \\
\text { deviation }\end{array}$ \\
\hline \multirow{4}{*}{$\begin{array}{l}\text { 1.Learning idioms is an important } \\
\text { part of learning English language }\end{array}$} & disagree & 9.0 & 9 & \multirow{4}{*}{3.1700} & \multirow[b]{4}{*}{.62044} \\
\hline & undetermined & 68.0 & 68 & & \\
\hline & agree & 20.0 & 20 & & \\
\hline & strongly agree & 3.0 & 3 & & \\
\hline \multirow[t]{4}{*}{ 2. I'm good at learning idioms. } & strongly disagree & 4.0 & 4 & \multirow[t]{4}{*}{2.5400} & \multirow[t]{4}{*}{.79671} \\
\hline & disagree & 53.0 & 53 & & \\
\hline & undetermined & 28.0 & 28 & & \\
\hline & agree & 15.0 & 15 & & \\
\hline \multirow{4}{*}{$\begin{array}{l}\text { 3. I like to use idioms in } \\
\text { speaking and writing English } \\
\text { language. }\end{array}$} & disagree & 2.0 & 2 & \multirow[t]{4}{*}{4.3200} & \multirow[t]{4}{*}{.70896} \\
\hline & undetermined & 8.0 & 8 & & \\
\hline & agree & 46.0 & 46 & & \\
\hline & strongly agree & 44.0 & 44 & & \\
\hline \multirow{3}{*}{$\begin{array}{l}\text { 4. I want to learn a variety of } \\
\text { idioms as part of learning English } \\
\text { language. }\end{array}$} & undetermined & 5.0 & 5 & \multirow[t]{3}{*}{4.4800} & \multirow[t]{3}{*}{.59425} \\
\hline & agree & 42.0 & 42 & & \\
\hline & strongly agree & 53.0 & 53 & & \\
\hline \multirow[t]{4}{*}{ 5. Idioms are easy to learn } & strongly disagree & 14.0 & 14 & \multirow[t]{4}{*}{2.1900} & \multirow[t]{4}{*}{.70632} \\
\hline & disagree & 56.0 & 56 & & \\
\hline & undetermined & 27.0 & 27 & & \\
\hline & agree & 3.0 & 3 & & \\
\hline \multirow[t]{4}{*}{ 6. Idioms are easy to use } & strongly disagree & 17.0 & 17 & \multirow[t]{4}{*}{2.1900} & \multirow[t]{4}{*}{.76138} \\
\hline & disagree & 51.0 & 51 & & \\
\hline & undetermined & 28.0 & 28 & & \\
\hline & Agree & 4.0 & 4 & & \\
\hline \multirow{4}{*}{$\begin{array}{l}\text { 7. I have a dictionary specifically } \\
\text { for idioms. }\end{array}$} & strongly disagree & 9.0 & 9 & \multirow[t]{4}{*}{2.3100} & \multirow[t]{4}{*}{.76138} \\
\hline & disagree & 60.0 & 60 & & \\
\hline & undetermined & 22.0 & 22 & & \\
\hline & agree & 9.0 & 9 & & \\
\hline \multirow{3}{*}{ 8. I am good at using idioms. } & strongly disagree & 34.0 & 34 & \multirow[t]{3}{*}{1.8300} & .69711 \\
\hline & disagree & 49.0 & 49 & & \\
\hline & undetermined & 17.0 & 17 & & \\
\hline 9. Idioms are difficult to & disagree & 5.0 & 5 & 4.2400 & .79290 \\
\hline understand because of the lack of & undetermined & 7.0 & 7 & & \\
\hline cultural background behind the & agree & 47.0 & 47 & & \\
\hline idioms. & strongly agree & 41.0 & 41 & & \\
\hline 10. Idioms are difficult because & undetermined & 2.0 & 2 & 4.4000 & \\
\hline they are not part of the courses' & agree & 56.0 & 56 & & .53182 \\
\hline & strongly agree & 42.0 & 42 & & \\
\hline 11. Idioms are difficult because & strongly disagree & 6.0 & 6 & 2.6500 & .60927 \\
\hline they are not taught well in class. & disagree & 24.0 & 24 & & \\
\hline & undetermined & 69.0 & 69 & & \\
\hline & agree & 1.0 & 1 & & \\
\hline 12. Idioms are difficult because the & strongly disagree & 3.0 & 3 & 3.7400 & .81178 \\
\hline cultural courses I studied were not & disagree & 4.0 & 4 & & \\
\hline efficient. & undetermined & 19.0 & 19 & & \\
\hline & agree & 64.0 & 64 & & \\
\hline & strongly agree & 10.0 & 10 & & \\
\hline
\end{tabular}


Appendix C 2: The frequencies, percentages, mean and standard deviation of the participants' strategies of learning English idioms and idiomatic expressions.

Table 2. The frequencies, percentages, mean and standard deviation of the participants' strategies of learning English idioms and idiomatic expressions.

\begin{tabular}{|c|c|c|c|c|c|}
\hline $\begin{array}{l}\text { Strategies for learning English } \\
\text { idioms }\end{array}$ & & Percent & Frequency & Mean & $\begin{array}{l}\text { Standard } \\
\text { deviation }\end{array}$ \\
\hline \multirow{4}{*}{$\begin{array}{l}\text { 1. I can predict the meaning of } \\
\text { idioms. }\end{array}$} & never & 35.0 & 35 & \multirow{4}{*}{1.8000} & \multirow[t]{4}{*}{.69631} \\
\hline & seldom & 51.0 & 51 & & \\
\hline & sometimes & 13.0 & 13 & & \\
\hline & frequently & 1.0 & 1 & & \\
\hline \multirow{4}{*}{$\begin{array}{l}\text { 2. I use verbal (textual or audio) } \\
\text { and visual information help to } \\
\text { activate my knowledge of idioms }\end{array}$} & never & 2.0 & 2 & \multirow[t]{4}{*}{3.7500} & \multirow[t]{4}{*}{.74366} \\
\hline & seldom & 4.0 & 4 & & \\
\hline & sometimes & 27.0 & 27 & & \\
\hline & always & 67.0 & 67 & & \\
\hline \multirow{4}{*}{$\begin{array}{l}\text { 3. I guess the overall meaning } \\
\text { of an idiom through breaking } \\
\text { it into parts and guessing the } \\
\text { meaning of their constituent } \\
\text { words. }\end{array}$} & never & 2.0 & 2 & \multirow[t]{4}{*}{3.1700} & \multirow[t]{4}{*}{.71145} \\
\hline & seldom & 12.0 & 12 & & \\
\hline & sometimes & 53.0 & 53 & & \\
\hline & frequently & 33.0 & 33 & & \\
\hline \multirow{4}{*}{$\begin{array}{l}\text { 4. I can figure out an idiom from an } \\
\text { equivalent one in my language. }\end{array}$} & seldom & 2.0 & 2 & \multirow[t]{4}{*}{4.4000} & \multirow[t]{4}{*}{.65134} \\
\hline & sometimes & 3.0 & 3 & & \\
\hline & frequently & 48.0 & 48 & & \\
\hline & always & 47.0 & 47 & & \\
\hline \multirow{4}{*}{$\begin{array}{l}\text { 5.I translate the literal meaning into } \\
\text { my L1 (first language) to } \\
\text { understand } \\
\text { idioms. }\end{array}$} & seldom & 1.0 & 1 & \multirow[t]{4}{*}{4.2400} & \multirow[t]{4}{*}{.75371} \\
\hline & sometimes & 11.0 & 11 & & \\
\hline & frequently & 31.0 & 31 & & \\
\hline & always & 57.0 & 57 & & \\
\hline \multirow{4}{*}{$\begin{array}{l}\text { 6.I learn idioms through group } \\
\text { discussion }\end{array}$} & never & 4.0 & 4 & \multirow[t]{4}{*}{2.5400} & \multirow[t]{4}{*}{.59323} \\
\hline & seldom & 39.0 & 39 & & \\
\hline & sometimes & 56.0 & 56 & & \\
\hline & frequently & 1.0 & 1 & & \\
\hline \multirow{3}{*}{$\begin{array}{l}\text { 7. I learn idioms through retelling } \\
\text { and paraphrasing. }\end{array}$} & never & 22.0 & 22 & \multirow[t]{3}{*}{2.0100} & \multirow[t]{3}{*}{.67412} \\
\hline & seldom & 55.0 & 55 & & \\
\hline & sometimes & 23.0 & 23 & & \\
\hline 8.I learn idioms with clear literal & sometimes & 23.0 & 23 & 4.0900 & .73985 \\
\hline meaning & frequently & 45.0 & 45 & & \\
\hline & always & 32.0 & 32 & & \\
\hline 9. I learn idioms with rich & sometimes & 16.0 & 16 & 3.9900 & .55949 \\
\hline illustration. & frequently & 69.0 & 69 & & \\
\hline & always & 15.0 & 15 & & \\
\hline 10. When facing a difficult idiom, I & seldom & 9.0 & 9 & 3.4900 & .65897 \\
\hline ignore it. & sometimes & 33.0 & 33 & & \\
\hline & frequently & 58.0 & 58 & & \\
\hline 11. I learn only familiar idioms & seldom & 1.0 & 1 & & .59246 \\
\hline with familiar vocabulary. & sometimes & 8.0 & 8 & & \\
\hline & frequently & 66.0 & 66 & 4.1500 & \\
\hline & always & 25.0 & 25 & & \\
\hline 12. I use many different strategies & sometimes & 8.0 & 8 & 4.3700 & .63014 \\
\hline when & frequently & 47.0 & 47 & & \\
\hline earning idioms. & always & 45.0 & 45 & & \\
\hline 13. I learn idioms which have & never & 63.0 & 63 & 1.4700 & 1.08670 \\
\hline multi-word combination & seldom & 35.0 & 35 & & \\
\hline & sometimes & 2.0 & 2 & & \\
\hline 14. I learn idioms used in used & seldom & 2.0 & 2 & 3.6100 & .52982 \\
\hline different media. & sometimes & 35.0 & 35 & & \\
\hline & Frequently & 63.0 & 63 & & \\
\hline
\end{tabular}


IJALEL 5(6): 119-133, 2016

133

\begin{tabular}{|c|c|c|c|c|c|}
\hline \multirow{4}{*}{$\begin{array}{l}15 . \text { I learn idioms through different } \\
\text { readings. }\end{array}$} & seldom & 6.0 & 6 & \multirow[t]{4}{*}{3.6300} & \multirow[t]{4}{*}{.71992} \\
\hline & sometimes & 33.0 & 33 & & \\
\hline & frequently & 53.0 & 53 & & \\
\hline & always & 8.0 & 8 & & \\
\hline \multirow{3}{*}{$\begin{array}{l}\text { 16. I up look unknown idioms in } \\
\text { the dictionary. }\end{array}$} & sometimes & 24.0 & 24 & \multirow[t]{3}{*}{4.1100} & \multirow[t]{3}{*}{.76403} \\
\hline & frequently & 35.0 & 35 & & \\
\hline & always & 41.0 & 41 & & \\
\hline \multirow{2}{*}{$\begin{array}{l}\text { 17. I guess the meaning of idioms } \\
\text { through the context. }\end{array}$} & frequently & 30.0 & 30 & \multirow[t]{2}{*}{4.6200} & \multirow[t]{2}{*}{.50812} \\
\hline & always & 69.0 & 69 & & \\
\hline \multirow{2}{*}{$\begin{array}{l}\text { 18. I need to know what other } \\
\text { strategies I can use to make better } \\
\text { sense of idioms. }\end{array}$} & frequently & 22.0 & 22 & \multirow[t]{2}{*}{4.7800} & \multirow[t]{2}{*}{.41633} \\
\hline & always & 78.0 & 78 & & \\
\hline
\end{tabular}

